\title{
Um Panorama da Pesquisa em Disciplinas de Estágio Supervisionado em Cursos Superiores a Distância no Brasil
}

\section{A Perspective of the Research in Supervised Internship} in Distance Courses in Higher Education in Brazil

\author{
Marcelo Werneck Barbosa ${ }^{1}$ \\ 1 PUC Minas Virtual / Pontifícia \\ Universidade Católica de Minas Gerais. \\ Av. 31 de março, 1020, Dom Cabral, \\ Belo Horizonte, MG - Brasil. \\ mwerneck@pucminas.br
}

\section{Resumo}

Este estudo teve como objetivo traçar um panorama da pesquisa sobre a disciplina Estágio Supervisionado em cursos superiores a distância no Brasil. Por meio de uma revisão da literatura, foram identificadas as principais características dos estudos realizados até os dias atuais. Foi observada a concentração de trabalhos do tipo relato de experiência; tais relatos se concentram em cursos $100 \%$ a distância, ministrados em universidades públicas, em cursos de licenciatura e formação de professores, sobretudo na área de Pedagogia. Como contribuições deste trabalho, destaca-se, além da observação desse panorama de publicações, a identificação de lacunas de pesquisa na área, como a falta de relatos da orientação de estágio em cursos da área de Gestão, em universidades particulares e ainda abrangendo a modalidade semipresencial, uma tendência para as universidades no Brasil.

Palavras-chave: Educação a distância, Estágio supervisionado, Estágio curricular, Formação de professores. 


\section{A Perspective of the Research in Supervised Internship in Distance Courses in Higher Education in Brazil}

\section{Abstract}

\section{Research Overview of Supervised Internship Discipline in Distance Higher Education in Brazil}

The objective of this study was to present an overview of the research on the Supervised Internship discipline for Distance Higher Education in Brazil. By means of a literature review, the main characteristics of the existing research were identified. The study observed a concentration of published work based on experience reports and that such reports are from $100 \%$ at distance programs, taught in public universities, at the undergraduate level, especially in the area of Pedagogy. As a contribution of this work, it can be highlighted that, besides the research overview, the study also identified research gaps, such as the lack of reports about internship orientation in the area of Business Management, in private universities, and in blended courses, which is a strong trend in distance learning in Brazil.

Keywords: Distance higher Education, Supervised Internship, Teaching Preparation program.

\section{Introdução}

A preocupação com o estágio remonta às origens dos cursos de formação de professor. Ela informa as inquietações sobre questões que dizem respeito às relações entre teoria e prática, conteúdo e forma, saberes disciplinares e saberes pedagógicos, espaço de formação e espaço de exercício profissional (Neto \& Santiago, 2015). Um pouco diferente da prática de ensino, o estágio é uma etapa da formação profissional desenvolvida presencialmente pelo estudante no futuro campo de trabalho, sendo estruturada, mediada, orientada, acompanhada e avaliada pela instituição formadora e supervisionada pela instituição que é campo de estágio (Will, 2012). O Estágio Supervisionado (ES) é, portanto, qualquer atividade que propicie ao aluno adquirir experiência profissional específica e que contribua de forma eficaz para sua absorção pelo mercado de trabalho. Podem ser consideradas as experiências de convivência em um ambiente de trabalho com cumprimento de tarefas com prazos estabelecidos, trabalho em um ambiente hierarquizado e com componentes cooperativistas ou corporativistas. O objetivo do Estágio Supervisionado é proporcionar ao aluno a oportunidade de aplicar seus conhecimentos acadêmicos em situações da prática profissional clássica, criando a possibilidade do exercício de suas habilidades. Espera-se que, com isso, o aluno tenha a opção de incorporar atitudes práticas e adquirir uma visão crítica de sua área de atuação profissional (Oliveira \& Cunha, 2006). O ES é de suma importância em qualquer área de atuação, podendo ser compreendido como um momento de aproximação com seu campo de atuação profissional, visto que é de suma importância a articulação entre teoria e prática para a construção do conhecimento (Freire \& Lima, 2013). O Estágio deve ser entendido como um componente curricular e uma prática formadora que perpassa o processo formativo, estendendo-se ao longo do curso de formação profissional, em que se efetiva uma relação entre o espaço de formação inicial e o espaço do trabalho profissional, sob a responsabilidade de uma equipe de professores (Neto \& Santiago, 2015).

A orientação da prática de Estágio assume nomes diversos em cada curso ou área de conhecimento. Neste texto, será utilizado o termo Estágio Supervisionado, mas ressalta-se que nomes como Estágio 
Curricular, Estágio Orientado ou mesmo Práticas de Ensino podem ser usados e são encontrados em trabalhos acadêmicos sobre o tema. De qualquer forma, em todos os casos considera-se essa disciplina como o espaço pré-profissional em que o estudante tem contato direto com a escola campo de estágio e seu cotidiano. Sob a supervisão de um professor da instituição formadora, o estágio oportuniza a realização de atividades diversas no campo de trabalho, objetivando a compreensão de sua organização e dinâmica (Neto \& Santiago, 2015). O estágio possibilita estudos práticos, exigindo dos alunos postura e articulação no processo de ensino e aprendizagem e conhecimento das práticas laborais, sendo um período probatório. Assim, a aprendizagem e a experiência adquiridas nesse momento apoiam a formação de sua visão global, mercadológica e para a vida acadêmica (Cruz, 2012).

Em cursos a distância, surgem questionamentos sobre como deve ser a condução da disciplina de Estágio Supervisionado. A princípio, o ES em Educação a Distância (EaD) não tem o acompanhamento in loco do professor orientador porque o curso é a distância. Portanto, em muitos casos a supervisão é realizada por intermédio de instrumentos avaliativos, fichas de controle e uma parceria muito próxima com as organizações em que o aluno está inserido (Medina \& Prudente, 2012). Há outros autores, entretanto, que acreditam que mesmo em cursos a distância o estágio curricular deve ser obrigatoriamente realizado em momentos presenciais, assim como algumas outras atividades (Santos \& Sabbatini, 2013). De qualquer forma, o Estágio Supervisionado em EaD é uma proposta que só se viabiliza coletivamente. As ações a serem desenvolvidas advêm de um processo sistêmico que exige equipes multidisciplinares que atuem de forma harmônica. A construção do conhecimento cada vez mais se dá de modo colaborativo, baseado na coautoria e no trabalho em rede (Will, 2012). Além disso, o professor ou orientador de estágio em EaD precisa adquirir saberes relacionados à cultura digital. A EaD exige do professor um novo olhar em relação à educação, pois possui particularidades diferentes das de um ensino nos moldes tradicionais (Santos \& Sabbatini, 2013).

Apesar da evolução e ampliação de cursos a distância no Brasil, ainda são encontrados poucos estudos sobre Estágio Supervisionado, mesmo sendo essa disciplina tão importante para a formação dos egressos das universidades. Dessa forma, faz-se necessário compreender como tem sido realizada a prática e a pesquisa em Estágio Supervisionado em cursos a distância no país. Por isso, este estudo tem como objetivo realizar um estudo exploratório para caracterizar a pesquisa em Estágio Supervisionado em cursos superiores a distância no Brasil. Por meio de uma revisão da literatura, foram identificadas as principais características dos estudos realizados até então. Pretende-se, dessa maneira, identificar lacunas e oportunidades de pesquisa que possam contribuir para o avanço da área.

O restante deste artigo está organizado da seguinte forma: a Seção 2 apresenta o referencial teórico, avançando na compreensão de temas relacionados ao Estágio Supervisionado na modalidade EaD. A Seção 3 descreve a metodologia utilizada neste estudo, enquanto a Seção 4 apresenta os resultados deste trabalho. A Seção 5 apresenta conclusões do trabalho, suas limitações e possibilidades de trabalhos futuros.

\section{O Estágio Supervisionado a Distância}

O estágio se configura como um campo de conhecimento, não devendo ser reduzido apenas a uma atividade prática instrumental. Por ele, ocorre a interação com o campo social e o desenvolvimento de práticas educativas. O Estágio é considerado um espaço propiciador da reflexão, uma oportunidade de associar a prática com a teoria. A prática do estágio curricular é de extrema importância para os alunos em formação, pois é o momento de observar a realidade das organizações e instituições, possibilitando a oportunidade de refletir sobre a teoria aprendida durante o curso, associando com sua prática de forma contextualizada (Freire \& Lima, 2013). Em muitos cursos, o estágio não é uma atividade facultativa, mas uma das condições primordiais para a obtenção do respectivo diploma. É imprescindível e compreendido como o tempo de aprendizagem que, por meio de um período de duração, um aluno permanece em 
algum lugar ou ofício para aprender a prática e depois exercer a profissão (Medina \& Prudente, 2012). $O$ Estágio Supervisionado, quando bem orientado pelos responsáveis, conseguem alimentar o desejo do aluno pela experiência prática, pela teoria e por difundir esse conhecimento (Cruz, 2012).

O estágio é, dessa forma, um modo especial de formação teórico-prática que ocorre em instituições educacionais formais e/ou não formais, em que o estagiário assume efetivamente o papel de professor e realiza outras atividades inerentes ao cotidiano educativo, desenvolvendo suas competências (Will, 2012). É fácil compreender que o Estágio Supervisionado, talvez mais do que outros componentes curriculares, traz essa mutualidade, em que os que ensinam e os que aprendem são sujeitos de um processo - mais que de formação, de construção e de criação (Oliveira \& Cunha, 2006). Com isso, pretende-se facilitar e ao mesmo tempo valorizar o Estágio Acadêmico como atividade pedagógica, visando proporcionar ao aluno oportunidade de verificar ou aplicar teorias aprendidas no conteúdo das diversas disciplinas para, desse modo, conseguir um real aproveitamento nos seus estudos (Cruz, 2012). Por fim, com a prática do estágio é possível construir o perfil do profissional, buscando intervir na realidade de forma crítica, ampliando conhecimentos, habilidades e competências. O estágio deve partir da pesquisa, reflexão e participação, ampliando sua formação curricular, associando a teoria e a prática. Deve ser um momento de pesquisa e ação diante da realidade escolar (Freire \& Lima, 2013).

Apesar de não ser o foco deste estudo, é importante ressaltar que existe um conjunto de documentos oficiais que normatizam o Estágio Supervisionado dos cursos de formação de professores, tais como a Lei de Diretrizes e Bases da Educação Nacional (LDBEN) - Lei n. 9.394/96; as Diretrizes Curriculares Nacionais; e a Lei n. 11.788/08, que dispõe sobre o estágio de estudantes no Brasil (Medina \& Prudente, 2012).

Os estágios na modalidade a distância ainda têm muita semelhança com o formato tradicional do ensino e envolvem planejamento, observação, e, no caso de professores de licenciatura, a docência (Kanashiro, Noal, Rocha \& Burigato, 2011). Na Educação a Distância, a prática do estágio é um desafio constante, considerando a função dos cursos de licenciatura na formação de professores para educação básica (Silva, Freitas \& Alcoforado, 2010). No entanto, considerando que o aluno da EaD, de maneira geral, é também um trabalhador, há uma série de dificuldades para a realização de estágios (Kanashiro et al., 2011).

O campo da formação de professores na modalidade de EaD vem ganhando atualmente espaço e tem sido procurado por uma significativa parcela do público que almeja o diploma de ensino superior. Os motivos pelos quais essa procura vem crescendo podem ser discutidos tanto no âmbito das políticas de ensino superior como também pelas questões socioeducacionais com que especificamente os cursos a distancia podem acenar (Pierro, Santos \& Drummond, 2012). O estágio deve ser visto como um componente curricular fundamental na formação de alunos e professores, especialmente porque oportuniza a articulação entre teoria e prática e, assim, potencializa a construção da identidade de professor (Cruz, 2012). O professor em formação deve ficar ciente dos desafios impostos à profissão docente, mas antes de tudo o estágio deve se constituir em um momento satisfatório de ensino e de aprendizagens advindas inclusive das dificuldades enfrentadas pela profissão. É possível que o estagiário não apreenda totalmente a prática profissional docente no estágio, pois este é insuficiente para que o professor em formação entenda os complexos problemas que enfrentará na escola, no seu dia a dia como profissional (Feldkercher, 2011), mas nem por isso deixa de ser um importante momento de prática e contato com a vida profissional.

\section{Metodologia}

Este trabalho pode ser caracterizado como um estudo exploratório, realizado por meio de uma revisão da literatura com o objetivo de identificar pesquisas e experiências práticas em disciplinas de Estágio Supervisionado a distância. Diferentemente de outras revisões de literatura, sobretudo as sistemáticas, que 
restringem as buscas por artigos em bases de dados ou revistas, este estudo optou por ampliar o domínio de buscas para a web em geral, visando encontrar um maior número de estudos que abordam experiências e estudos sobre Estágio Supervisionado a distância no Brasil. Inicialmente, as buscas foram realizadas em revistas qualificadas da área de Educação: Linhas Críticas, EAD em Foco e Revista de Novas Tecnologias na Educação. Entretanto, o número de artigos encontrados nessas revistas foi pequeno, o que motivou a ampliação da busca para toda a web. A ferramenta de busca utilizada nesse momento foi o Google Acadêmico. Esse mesmo procedimento foi adotado no trabalho de Wangenheim, Kochanski \& Savi (2009).

A pesquisa foi realizada usando a string de busca "estágio" AND ("virtual" OR "distância"). Como critério de inclusão, os estudos precisavam abordar temas teóricos sobre o estágio ou relatos de experiência em disciplinas de Estágio Supervisionado a distância. Os resultados retornados pela máquina de busca foram processados da seguinte forma: os títulos foram lidos e, se necessário, os resumos para identificar se o trabalho atendia aos critérios de inclusão definidos. Os trabalhos que atenderam aos critérios foram lidos completamente; algumas características do estudo foram analisadas e são apresentadas na próxima seção.

\section{Resultados e Discussão}

Após a realização da pesquisa, dezesseis estudos cumpriram os critérios de inclusão definidos no planejamento do trabalho. Alguns dados desses estudos são apresentados no Quadro 1 e discutidos em seguida. Em resumo, pode-se observar que a maioria dos estudos:

- adotou a metodologia de relato de experiência;

- adotou como estudo cursos na modalidade 100\% a distância;

- foi realizada em universidades públicas;

- foi realizada em cursos de licenciatura, sendo a maior parte em cursos de Pedagogia.

Quadro 1: Resultados da Revisão

\begin{tabular}{|l|l|l|l|l|l|}
\hline Referência & Metodologia & $\begin{array}{l}\text { Modalida- } \\
\text { de }\end{array}$ & $\begin{array}{l}\text { Particular/ } \\
\text { Pública }\end{array}$ & $\begin{array}{l}\text { Licenciatura/ } \\
\text { Bacharelado }\end{array}$ & $\begin{array}{l}\text { Área do conheci- } \\
\text { mento do curso }\end{array}$ \\
\hline (Silva et al., 2010) & $\begin{array}{l}\text { Relato de } \\
\text { Experiência }\end{array}$ & EaD & Pública & Licenciatura & Computação \\
\hline (Moraes, 2015) & $\begin{array}{l}\text { Relato de } \\
\text { Experiência }\end{array}$ & EaD & Pública & Licenciatura & Letras \\
\hline $\begin{array}{l}\text { (Pierro et al., 2012) } \\
\text { (Medina \& Pruden- } \\
\text { te, 2012) }\end{array}$ & $\begin{array}{l}\text { Relato de } \\
\text { Experiência } \\
\text { Experiência }\end{array}$ & $\begin{array}{l}\text { Semipre- } \\
\text { sencial }\end{array}$ & Pública & Licenciatura & Pedagogia \\
\hline (Cruz, 2012) & Conceitual & - & Particular & Licenciatura & Educação Física \\
\hline $\begin{array}{l}\text { (Raabe \& Cybis, } \\
\text { 2004) }\end{array}$ & $\begin{array}{l}\text { Relato de } \\
\text { Experiência }\end{array}$ & EaD & Pública & Bacharelado & $\begin{array}{l}\text { Informação/ } \\
\text { Engenharia de } \\
\text { Usabilidade }\end{array}$ \\
\hline $\begin{array}{l}\text { (Feldkercher, 2011) } \\
\text { Experiência }\end{array}$ & $\begin{array}{l}\text { Relato de } \\
\text { exaD }\end{array}$ & Pública & Licenciatura & Matemática \\
\hline $\begin{array}{l}\text { (Oliveira \& Cunha, } \\
\text { 2006) }\end{array}$ & $\begin{array}{l}\text { Relato de } \\
\text { Experiência }\end{array}$ & EaD & Pública & Licenciatura & Pedagogia \\
\hline $\begin{array}{l}\text { (Patatt, 2010) } \\
\text { Experiência }\end{array}$ & EaD & Pública & Licenciatura & Letras \\
\hline
\end{tabular}




\begin{tabular}{|l|l|l|l|l|l|}
\hline $\begin{array}{l}\text { (Kanashiro et al., } \\
\text { 2011) }\end{array}$ & $\begin{array}{l}\text { Relato de } \\
\text { Experiência }\end{array}$ & EaD & Pública & Licenciatura & $\begin{array}{l}\text { Letras, } \\
\text { Matemática e } \\
\text { Pedagogia }\end{array}$ \\
\hline $\begin{array}{l}\text { (Santos \& Sabbatini, } \\
\text { 2013) }\end{array}$ & $\begin{array}{l}\text { Relato de } \\
\text { Experiência }\end{array}$ & EaD & Pública & Licenciatura & Pedagogia \\
\hline (Will, 2012) & $\begin{array}{l}\text { Relato de } \\
\text { Experiência }\end{array}$ & EaD & Privada & Licenciatura & Pedagogia \\
\hline (Lima, 2012) & Conceitual & - & - & - & - \\
\hline $\begin{array}{l}\text { (Freire \& Lima, } \\
\text { 2013) }\end{array}$ & $\begin{array}{l}\text { Relato de } \\
\text { Experiência }\end{array}$ & EaD & Pública & Licenciatura & - \\
\hline $\begin{array}{l}\text { (Ziede, Charczuk \& } \\
\text { Nevado, 2011) }\end{array}$ & $\begin{array}{l}\text { Relato de } \\
\text { Experiência }\end{array}$ & EaD & Pública & Licenciatura & Pedagogia \\
\hline $\begin{array}{l}\text { (Neto \& Santiago, } \\
\text { 2015) }\end{array}$ & $\begin{array}{l}\text { Relato de } \\
\text { Experiência }\end{array}$ & EaD & Pública & Licenciatura & Pedagogia \\
\hline
\end{tabular}

O Estágio Supervisionado é um componente fundamental nos cursos de Licenciatura. Nas Diretrizes Curriculares Nacionais desses cursos, o Estágio Supervisionado constitui processo de transição profissional que procura ligar duas lógicas (educação e trabalho) e que proporciona ao estudante a oportunidade de treinar as competências e habilidades que já detém sob supervisão de um profissional da área (Medina \& Prudente, 2012). Assim, o Estágio Supervisionado deve possibilitar um envolvimento experiencial e interativo dos licenciandos com a instituição escolar, criando condições de aprendizagem que podem propiciar a aquisição de saberes profissional (Pierro et al., 2012). O Estágio Supervisionado é importante, pois tem o intuito de construir um novo professor, algo essencial em disciplinas de formação, seja na graduação, seja na especialização (Cruz, 2012).

Pelo próprio cunho prático das disciplinas de Estágio, entende-se como natural a existência de muitos relatos de experiência encontrados neste estudo. Entretanto, os resultados apontam lacunas que podem ser exploradas em estudos e relatos futuros, como a concentração dos estudos em universidades públicas e em cursos $100 \%$ a distância. Dado que as universidades particulares concentram a maioria dos cursos a distância, segundo o Censo Abed de 2016/2017 (Abed, 2017), é fundamental compreender como os Estágios Supervisionados acontecem nessas universidades e compartilhar experiências. Esse mesmo censo observa o crescimento de 51\% na oferta de EaD em instituições privadas entre 2011 e 2015. Além disso, com o aumento dos cursos semipresenciais, almejado por $23 \%$ das instituições pesquisadas, tornase muito relevante compreender como a disciplina de Estágio pode ser ministrada nesse tipo de modalidade e que recursos metodológicos têm sido utilizados.

Por fim, pode-se observar que faltam relatos de experiência sobre Estágio Supervisionado em cursos da área de Gestão, como Administração ou Ciências Contábeis. Segundo o Censo Abed de 2016/2017, o curso de Administração é o segundo curso a distância mais procurado no Brasil. Além disso, é um curso em que os alunos conseguem rápida inserção no mercado de trabalho. Dessa forma, acompanhar como suas atividades de estágio têm sido realizadas e como os cursos têm implantado tal disciplina, com a possibilidade de discutir técnicas diferenciadas, é de fundamental importância.

Foi possível ainda identificar algumas diferenças que tais estudos apontam entre as disciplinas de Estágio Supervisionado em cursos a distância e em cursos presenciais. Há diferenças entre os recursos pedagógicos utilizados: enquanto nos cursos presenciais foi citado o uso de aulas presenciais, nos cursos a distância foram citadas webconferência, videoaulas, uso de ambiente virtual de aprendizagem (Feldkercher, 2011) e diário online (Ziede et al., 2011). Destaca-se ainda que o material didático de qualidade deve apresentar caráter formador e não instrutivo, que em seu planejamento haja possibilidade de intervenções, críticas, questionamentos e uso de diferentes mídias (Oliveira \& Cunha, 2006). Além disso, no ensino 
virtual, o aluno tem a possibilidade de organizar seu tempo de estudo (Freire \& Lima, 2013) e recorrer a tutores virtuais.

Entretanto, há também semelhanças entre as disciplinas, como as exigências de documentação detalhada e a necessidade de seguro de vida para o aluno em período de cumprimento de suas horas de estágio (Freire \& Lima, 2013). Ainda há técnicas que podem ser usadas em ambas as modalidades, como a observação participativa no exercício do estágio; a reflexão crítica e a analogia dos aspectos observados com o referencial teórico abordado no curso (Oliveira \& Cunha, 2006). Como aspectos negativos do Estágio Supervisionado realizado a distância, foram encontrados relatos de dificuldades de um acompanhamento mais cuidadoso com os estudantes, com as instituições concedentes e das ações desenvolvidas, a falta de estrutura para oficinas práticas, a ausência ou falta de comunicação com os acadêmicos (Freire \& Lima, 2013).

Para mostrar a evolução da pesquisa nos últimos anos, o Gráfico 1 apresenta o número de artigos publicados por ano, dentro da amostra analisada neste estudo. Pode-se observar que os artigos se concentram entre os anos de 2010 e 2013, não tendo sido observados estudos publicados nos dois últimos anos.

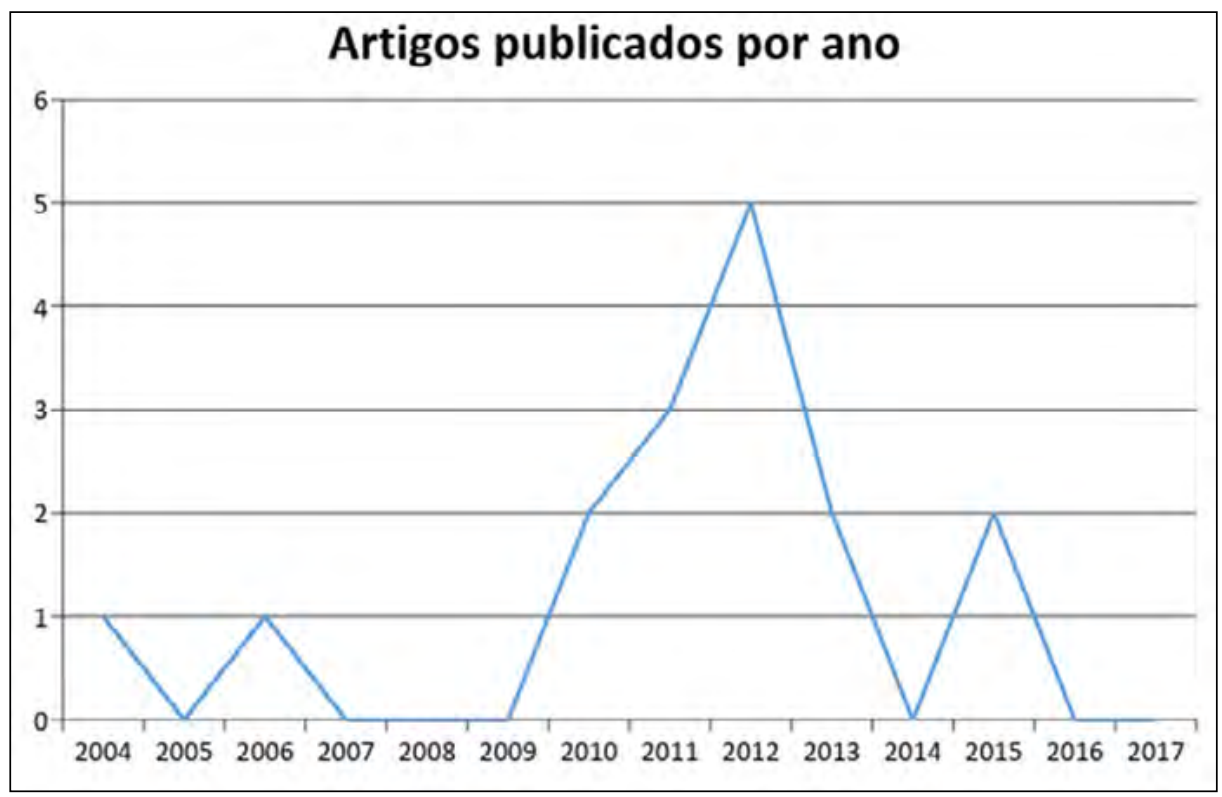

Gráfico 1: Artigos publicados por ano.

\section{Conclusão/Considerações Finais}

Este estudo teve como objetivo realizar um estudo exploratório para caracterizar a pesquisa em Estágio Supervisionado em cursos superiores a distância no Brasil. Por meio de uma revisão da literatura, foram identificadas as principais características dos estudos realizados até então. O estudo observou uma concentração de trabalhos publicados do tipo relato de experiência e que tais relatos se concentram em cursos $100 \%$ a distância, ministrados em universidades públicas, em cursos de licenciatura e formação de professores, sobretudo na área de Pedagogia. Como contribuição deste trabalho, destaca-se, além da observação desse panorama de publicações, a identificação de lacunas de pesquisa na área, como a falta de relatos da orientação de Estágio em cursos da área de Gestão, em universidades particulares e abrangendo a modalidade semipresencial, uma tendência para as universidades no Brasil.

Como limitações deste trabalho, pode-se destacar o fato de a pesquisa ter sido realizada na web, o que pode dificultar a limitação de um escopo mais específico para a realização da busca. Inicialmente, as buscas foram realizadas em revistas qualificadas da área de Educação, como Linhas Críticas, EaD em Foco e 
Revista de Novas Tecnologias na Educação. Entretanto, o número de artigos encontrados nessas revistas foi pequeno, o que motivou a ampliação da busca para toda a web. De qualquer maneira, o trabalho aponta tendências e lacunas relevantes para a pesquisa em Estágio Supervisionado. Além disso, outras bases científicas mais específicas, tais como, SciELO, Edubase, Periódicos Capes e os acervos de publicações de grandes universidades públicas que compartilham as suas pesquisas de mestrado e doutorado podem ser usados.

Como trabalho futuro, pretende-se investigar a prática de Estágio Supervisionado em cursos da área de Gestão, como Administração e Ciências Contábeis a distância, buscando verificar que métodos têm sido aplicados em tais cursos. Outra linha de investigação promissora é o estudo dessa disciplina em cursos semipresenciais.

\section{Referências Bibliográficas}

Abed (2017). Censo Abed 2016/2017. Disponível em: http://abed.org.br/censoead2016/Censo EAD 2016 portugues.pdf

Cruz, J. A. S. (2012). Estágio Supervisionado: fundamental para o crescimento profissional. Cadernos de Educação, Tecnologia e Sociedade, 3(1), 1-10. http://doi.org/10.14571/cets.v3.1-10p.

Feldkercher, N. (2011). O estágio na formação de professores presencial e a distância: a experiência do curso de Matemática da UFPel. Universidade Federal de Pelotas.

Freire, W. C. C. \& Lima, D. C. B. P. (2013). Estágio Curricular na EAD: desafios e possibilidades na licenciatura de um polo UAB. Revelli - Revista de Educação, Linguagem e Literatura de Inhumas, 5(2), 81-99.

Kanashiro, D. S. K., Noal, M. L., Rocha, P. G. da \& Burigato, S. (2011). O Estágio Supervisionado nos cursos de licenciatura da EAD/UFMS: métodos, resultados e desafios. Revista Novas Tecnologias na Educação (Renote), 9(2).

Lima, D. C. B. P. (2012). Didática e Estágio Curricular nos cursos de formação de professores a distância, 1792-1803. Brasília: Liber Livro.

Medina, A. C. R. \& Prudente, P. L. G. (2012). Estágio Supervisionado do curso de Educação Física - Licenciatura, modalidade a distância, da Universidade Fumec: um relato de experiência. Paideia, 9(12), 187-206.

Moraes, M. S. de (2015). Estágio de Docência e projetos de extensão em uma licenciatura em língua estrangeira em EaD no Espírito Santo. EaD Em Foco, 5(3), 128-141.

Neto, J. B. \& Santiago, E. (2015). Estágio Curricular: permanências e mudanças em um espaço tempo estruturador da formação de professores. Linhas Críticas, 46, 584-605.

Oliveira, E. S. G. \& Cunha, V. L. (2006). O Estágio Supervisionado na formação continuada docente a distância: desafios a vencer e construção de novas subjetividades. Revista de Educación a Distancia, 5(14), 1-18.

Patatt, C. R. (2010). O Estágio Supervisionado no curso de Letras a distância: relato de experiência prática. Linguagens e Cidadania, 12, 1-11.

Pierro, G. M. S., Santos, M. C. A. dos \& Drummond, R. (2012). Estágio Supervisionado: questões e desafios na formação de professores em EaD. In: Simpósio Internacional de Educação a Distância (pp. 1-9).

Raabe, R. O. \& Cybis, W. A. (2004). Estágio virtual à distância: um estudo de caso para o ensino de Engenharia de Usabilidade. Revista Novas Tecnologias na Educação (Renote), 2(1), 1-10. 
Santos, A. A. M. \& Sabbatini, M. (2013). A presença e o virtual na EaD: reflexão sobre o estágio supervisionado nesse contexto. In: VII Simpósio Nacional da Associação Brasileira de Pesquisadores em Cibercultura. Curitiba, PR.

Silva, I. M. M., Freitas, J. M. A. de \& Alcoforado, L. (2010). Estágio Curricular Supervisionado na Educação a Distância. In: Anais do $16^{\circ}$ Congresso Internacional de Educação a Distância Abed. Foz do Iguaçu, PR. (pp. 1-10).

Wangenheim, C. G. von, Kochanski, D. \& Savi, R. (2009). Revisão sistemática sobre avaliação de jogos voltados para aprendizagem de Engenharia de Software no Brasil. In Fórum de Ensino de Engenharia de Software (FEES), Simpósio Brasileiro de Engenharia de Software (SBES). Fortaleza, CE.

Will, D. E. M. (2012). A gestão do Estágio Curricular Supervisionado em Pedagogia a distância por meio das tecnologias de informação e comunicação. Cadernos Acadêmicos, 4(1), 79-103.

Ziede, M. K. L., Charczuk, S. B. \& Nevado, R. A. de (2011). Estágio Curricular Online em curso de Pedagogia a distância. Revista Novas Tecnologias na Educação (Renote), 9(1). 